\title{
Značaj sportskog marketinga za razvoj ekološke svesti kod posebnih grupa sportista
}

\section{The importance of sports marketing for the development of environmental awareness in sports special groups}

\author{
Vojkan Bižić ${ }^{1}$, Jovan Veselinović ${ }^{2}$, Srećko Bačevac ${ }^{3}$ \\ ${ }^{1}$ Fakultet za poslovne studije, Beograd, Srbija \\ ${ }^{1}$ Faculty of business studies, Belgrade, Serbia \\ ${ }^{2}$ Alfa BK Univerzitet, Fakultet za menadžment u sportu, Beograd, Srbija \\ ${ }^{2}$ Alfa BK University, Faculty of Sports Management, Belgrade, Serbia \\ ${ }^{3}$ Akademija Dositej, Beograd, Srbija \\ ${ }^{3}$ Dositej Academy, Belgrade, Serbia
}

Rad primljen: 30.12.2020, Rad prihvaćen: 20.02.2021.

Sažetak: Marketing u sportu dece sa posebnim potrebama, daje posebno izazovan zadatak pred svakoga ko želi da se bavi istraživanjem ove teme bilo da se radi o ekonomistima, ekolozima, defektolozima, profesorima fizičke kulture kao i mnogim drugim istraživačima. Ovo je poseban izazov za stučnjake ekonomske struke, da pokažu vezu marektinga, posebno marketinga u sportu i podsticanja dece sa posebnim potrebama da kroz bavljenje sportskim aktivnostima stiču znanja o značaju očuvanja životne sredine za njihov život, rad i bavljenje sportom. Cilj rada je da se ukaže na moguću primenu marketinga u sportu kod najmlađe populacije. Rezultati rada daju odgovor na pitanje kako raznovrsni integrisani marketinški kanali komunicranja mogu da doprinesu da se i ovako specifična populacija bavi sportom danas i razvije ekološku svet o značaju životne sredine za bavljenje sportom.

Ključne reči: sport, marketing u sportu, deca sa posebnim potrebama, ekologija, zaštita životne sredine.

\begin{abstract}
Marketing in the sport of children with special needs gives a particularly challenging task to anyone who wants to research this topic, whether it be economists, ecologists, defectologists, professors of physical culture and many other researchers. This is a particular challenge for economics professionals to show the connection between marketing, especially sports marketing and encouraging children with special needs to acquire knowledge about the importance of environmental protection for their livelihood, work and sports through their sports activities. The aim of the paper is to point out the possible application of marketing in sports in the youngest population. The results of the paper answer the question of how diverse integrated marketing channels of communication can contribute to the fact that such a specific population engages in sports today and develops an ecological world about the importance of the environment for sports.
\end{abstract}

Keywords: sports, marketing in sports, children with special needs, ecology, environmental protection.

1'orcid.org/0000-0002-4181-7784, e-mail:vbizic@yahoo.com

²orcid.org/0000-0001-7725-8358, e-mail: jovan.veselinovic@alfa.edu.rs

3orcid.org/0000-0002-9580-9667, e-mail: srecko.bacevac@gmail.com 


\section{UVOD / INTRODUCTION}

$\mathrm{U}$ radu obradićemo temu koja nije mnogo istražena u domenu savremnog marketinga u sportu, ne toliko na ovim prostorima. Osnove marketinga u sportu, deca sa posebnim potrebama u sportu, koji su to sve inovativni marketinški kanali komuniciranja koji najviše koriste deca sa posebnim potrebama, a i njihovi roditelji prilikom odabira kluba, sportske organizacije za bavljenje sporta njihove dece i kako sport može da utiče na podizanje ekološke svesti dece sa posebnim potrebama.

Sport i sve sportske delatnosti su posebna i specifična oblast ljudskog delovanja. Koliko je sport postao globalni fenomen govori i uticaj velikih različith podsistema društva kao što su politika, ekonomija, kultura, ekologija, privreda,a pored toga i delotvoran rad sa decom sa posebnim potrebama.

Velika je povezanost između ekologije i ekoloških performansi i sporta, kao preduslova za zdrav život. Relacija između sporta i ekologije kod nas na ovim prostorima predstavlja odnos novog vremena. Postoji kompletan odnos međusobnog dopunjavanja sporta i ekologije, jer oba elementa imaju isti ljudski smisao, odnosno vrednosti izražene kroz zajednički imenitelj, to je zdrav način života dece i odraslih.

Termin sport, počećemo sa značenjem reči sport. Latinska reč "disportare" znači "odneti” ili "raznositi" u prenosnom smislu "opustiti se ". U XIV veku "disport" dobija novo značenje i upotrebljava se za označenje "aktivnosti u slobodnom vremenu". Iz navedenog značenja engleske reči nastaje termin "sport". Značenje reči "sport" danas u svetu podrazumeva: "zadovoljstvo, ugodnost, razonodu, odmor, telesno vežbanje, takmičenje, trčanje i sl."

Razvojem savremenog društva, kao prateća pojava tog procesa razvijaju se i dobijaju sve veći značaj raznovrsne delatnosti koje obuhvataju pojam sporta, a posebno proces mondijalizacije sporta kao njegovog najvišeg dometa. Opravdanost i celishodnost ekonomskog pristupa fenomenu sporta potiče iz činjenice da je reč o nečemu što ne proučava samo jedna disciplina, kao i iz toga da se ovde radi o specifičnom redu pojava, odnosa i aktivnosti koje se ne sreću u ostalim područjima društvenog života i u kojima vladaju specifični ekonomski odnosi, koje istovremeno u celini i njihovoj unutrašnjoj povezanosti predstavljaju zaokružen sistem sa sopstvenom relativnom samostalnošću.

Sport predstavlja zadovoljenje potrebe čoveka za kretanjem i način konstruktivnog i zdravog korišćenja slobodnog vremena pojedinca. Sport predstavlja korisnu delatnost čoveka koja se ispoljava u kretanju, različitim oblicima telesnih vežbi i takmičenju ljudi. Ovo predstavlja gledište sporta sa aspekta sociologije, psihologije, filozofije i drugih društvenih nauka. Zajedničko stanovište moderne društvene nauke je da sport predstavlja korisnu delatnost. Sport čine više izvedenih pojmova, poput školskog sporta, rekreativnog sporta, takmičarskog (vrhunskog i kvalitetnog sporta), sportskog menadžmenta i slično. Osim po kvalitativnom nivou, sportove je moguće razvrstati i na olimpijske i neolimpijske. Međunarodna povelja o fizičkom vaspitanju i sportu, koju je UNESKO usvojio 1978. godine, u prvom članu naglašava da je „Bavljenje fizičkim vaspitanjem i sportom fundamentalno ljudsko pravo za sve" (Bižić, 2015). Fizička komponenta se odnosi na negovanje fizičkih i fizioloških osobina pojedinca, deluje kao korektiv (u smislu popravljanja nekih fizičkih nedostataka) što utiče na povećanje radne sposobnosti, produktivnosti i smanjivanje povreda na radu. Psihološki učinak se odnosi na jačanje volje i istrajnosti, odnosno disciplinu u izvođenju dobrovoljno prihvaćenih aktivnosti, sticanje i razvijanje samokontrole i kontrole sopstvenih postupaka (Hrnjica, 1991).

Pojam profesionalnog sporta podrazumeva takmičenja i sve njihove aspekte, odabranih, visoko selektiranih pojedinaca, koji se nazivaju vrhunskim sportistima i koji se sportom bave kao svojom profesijom za šta dobijaju adekvatnu materijalnu nadoknadu u skladu sa svojim sportskim dostignućima. Za pojam društvo postoji više različitih tumačenja i upotreba ovog termina, ali se obično pod tim podrazumeva grupa ljudi koja zajedno živi i radi u određenoj zajednici. Ovaj pojam ukazuje da njegovi članovi imaju neke zajedničke brige, obaveze, interese i ciljeve, pa se kao takav često koristi kao sinonim za narod jedne zemlje koja ima zajedničke institucije koje vode brigu o svojim građanima.

Sport ima veoma mnogo obeležja javne delatnosti i u tom smislu obavezan je da u odnosima sa javnošću izdrži i pozitivne i negativne odzive javnog auditorijuma, predstavljene obično kroz sredstva masovnog informisanja (Hall, 1992). Sportski subjekti koriste predmetnu metodu, najčešće za poboljšanje imidža. Za postupke i sportsku aktivnost, posebno za nivo sportskih rezultata,oni su odgovorni pred javnošću.Relacija između sporta i ekologije, kod nas, na ovim prostorima predstavlja odnos novog vremena. Postoji komplementaran odnos međusobnog dopunjavanja sporta i ekologije, jer oba elementa imaju isti ljudski smisao, odnosno vrednosti izražne kroz zajednički imenitelj - zdrav život - zdrav način života (Štakić, 2003). To međutim predstavlja stalnu brigu, stalne i različne aktivnosti na uspostavljanju, održavanju i unapređivanju relativno uravnoteženog odnosa između aktivnosti, odnosa i ponašanja individua i njihovih socijalnih objedinjavanja u globalno 
društvo, na očuvanju njihovog prirodnog i kulturno razvijeno, ustanovljenog ambienta.

$S$ obzirom da imaju isti smisao, iste ili identične ciljeve, nastaju i različite, brojne ekološke aktivnosti (formiraju se i povezuju razni eskološki pokreti) koji se intergišu sa područjem sporta. $U$ te ideje i projekte uključuju se prirodno-naučne i društvenonaučne discipline, zauzimajući globalne i strateške pozicije političkog faktora (Tomić, 2003).

Ekologija i sport imaju više toga zajedničkog nego što se na prvu pomisao to čini. Sport bilo kao takmičrski ili u okvirima sportske rekreacije sastavni je deo ekoloških akcija i izleta te je često nezaobilazni deo izložbi koje obuhvataju problematiku ekologije i etike. Da bi sport mogao dati potrebne i očekivane rezultate, posebno u masovnom sportu, u zajedničkim životom, u sredini zaštićenoj od razhih zagađenja, neophodan je adekvatni odnos celog društva, države i njenih institucija a posebno ljudski faktor prema ekološkoj problematici, jer u zagađenoj, kontaminiranoj okolini sam sport se ne bi mogao dovoljno rezultirati. Zbog toga treba i očekivati od društva da vodi računa o psihofizičkom zdravlju čoveka, koje ima odgovarajuće tradicije, da preuzme mere i unapređuje aktivnosti koje podstiču tu brigu.

Kod različitih vrsta sportova reazlikuju se posebne vrste sredina, na primer, sportovi na vodi, na zemji ili u vazduhu, sportovi pod vodom ili na snegu $i$ planinama, u zatvorenim ili otvorenim objektima u geografskim različitim sredinama, pod dejstvom različitih klimatskih uslova i faktora, u prirodnoj sredini ili u namenskim kultivisanim sredinama itd., a koje su na ovaj ili onaj način povezane sa ekologijom, odnosno zaštitom životne sredine.

\section{MATERIJALI I METODE / MATERIALS AND METHODS}

Jezičko određenje vezana za osobe sa smetnjama u razvoju još uvek su aktuelan problem za istraživače. Jedinstvenog stava još uvek nema, ali je većina saglasna da je važno izbeći terminologiju koja se smatra uvredljivom, omalovažavajućom i diskriminatorskom za osobe sa smetnjama u razvoju i invaliditetom. Danas su u upotrebi najviše termini osoba sa invaliditetom i dete sa smetnjama u razvoju i najnovije deca sa posebnim potrebama.

U praksi su dosta dugo upotrebljavani (i još uvek se koriste) termini:

1. hendikepirani; (Hrnjica,1991).

2. deca i omladina ometena u razvoju - dete kod koga je razvoj u određenom stepenu i kvalitetu poremećen (ometen), odnosno kod koga je pore- mećen normalan tok psihičkog i/ili fizičkog razvoja (Hrnjica, 1991).

3. deca sa smetnjama u razvoju - sva deca koja imaju teškoće u učenju, a koje mogu biti posledica ometenosti ili nekih drugih nepovoljnih okolnosti, pa im je potrebna posebna podrška i pomoć (Rajović, 2004).

4. lica kojima je potrebna posebna društvena podrška - osobe koje u nekom periodu razvoja imaju određene poteškoće, ali su im potrebe kao i kod svih drugih ljudi, samo je način njihovog zadovoljavanja različit; (Radoman, 2003).

5. netipične osobe - sva deca kojoj je potrebna neka vrsta akomodacije ili adaptacije u obrazovnom i životnom okruženju kako bi dostigli svoj puni obrazovni i socijalno-emotivni potencijal (Radoman, 2003).

6. deca ometena u razvoju - raznovrsne grupe čije su somatopsihičke varijacije izražene u toj meri da ometaju normalan razvoj njihovih adaptivnih sposobnosti. Ovim terminom se označavaju i deca sa različitim oblicima ometenosti, kao i deca sa disharmoničnim razvojem struktura psihomotornog sistema. Tu spadaju i deca koja zbog oštećenja nekih organa ili njihovih funkcija zahtevaju posebne vaspitno-obrazovne i rehabilitacione postupke kako bi se ometenost ublažila i eventualno otklonila (Čolin, 2005).

Kada je reč o funkcionalnim i razvojnim smetnjama kod dece, za klasifikaciju koju je kreirao istraživački tim OECD/CERI može se reći da je do sada bila opšte prihvaćena. Sadrži šest kategorija/ klasa funkcionalnih poremećaja.

(1) oštećenje senzornih funkcija (oštećenje vida, sluha, senzorni poremećaji taktilne osetljivosti, bola, dodira, kretanja i ravnoteže);

(2) poremećaji kognitivnih, intelektualnih, perceptivnih i funkcija pažnje (mentalna zaostalost svih stepena, teškoće u učenju, govorne disfunkcije, distrakcija pažnje raznog stepena, okulomotorni perceptivni poremećaji i sl.);

(3) poremećaji kontrole mišića (posebno oni koji ometaju ili otežavaju kretanje, neposrednu komunikaciju i komunikaciju deteta sa sredinom);

(4) oštećenja fizičkog zdravlja deteta (metabolički i fiziološki poremećaji);

(5) emocionalni poremećaji i poremećaji u organizaciji ponašanja (situacioni poremećaji emocija i ponašanja, hiperaktivno i hipoaktivno ponašanje, neuroze, psihoze, autizam, promene ponašanja izazvane oštećenjima nervnog sistema i emocionalne promene);

(6) spoljašnji faktori u odnosu na dete koji ometaju njegov razvoj i funkcionisanje u granicama 
sposobnosti (disfunkcionalne ili haotične porodice, neodgovorno ponašanje roditelja, zlostavljanje dece, teži oblici materijalnog, socijalnog i kulturnog zaostajanja porodice i sl.).

Osobe sa teškoćama u razvoju i invaliditetom predstavljaju veoma heterogenu grupu, koja u sebe uključuje veoma raznolik raspon preostalih sposobnosti, manifestacija oštećenja, a samim tim i različitih mogućnosti da se uključe u fizičke aktivnosti i sport, ali i različitih ciljeva koji se postavljaju u okviru ovih aktivnosti. Svetska zdravstvena organizacija (WHO) definiše invaliditet kao ograničenje, smanjenje ili ispad sposobnosti izvršenja neke fizičke aktivnosti. „Sve je vidljivija primena socioloških saznanja pri upravljanju sportom kao društvenom institucijom, kao i u proučavanju njegovih mogućnosti u realizaciji individualnih i društvenih potreba "Savremeni aspekti fizičkog vaspitanja, sporta i rekreacije" psihičke funkcije primerene životnoj dobi. Sport ima vaspitnu delatnost, ali mu to nije jedina funkcija (Lazor i dr, 2008).

\section{REZULTATI I DISKUSIJA / RESULTS AND DUSCUSSION}

Sport pored zdravstvene, ima moć da ojača zajednice i podrži razvoj inkluzivnih društva (Šiljak i dr., 2019).

Postojanje nezadovoljenih želja kod dece koja se redovno bave sportskim aktivnostima. Kako bismo dali zadovoljavajući odgovor na pitanje da li među decom sa posebnim potrebama postoji nezadovoljena želja za upražnjavanjem sporta ili sportskih aktivnosti, potrebno je da analiziramo podatke istraživanja iz nekoliko uglova. Pošto je decu moguće podeliti

(1) na onu koja se trenutno redovno bave nekim sportom ili sportskim aktivnostima,

(2) na onu koja se trenutno ne bave redovno, ali su se nekada bavila redovno, i

(3) na onu koja se nikada nisu redovno bavila bilo kakvim sportom ili sportskim aktivnostima, pot- rebno je ispitati postojanje moguće nezadovoljene želje za ovakvim bavljenjem među svakom od ove tri grupe dece (Bižić, 2020).

Za početak pogledajmo kojim se sportskim aktivnostima sve bave deca koja se redovno bave sportom. $U$ tu svrhu urađena je analiza sadržaja nad svim sportovima i aktivnostima koje su ispitanici naveli (nezavisno od toga da li se trenutno bave sportom). Ova analiza pokazala je da je sportske aktivnosti moguće podeliti na individualne i timske, a individualne je dodatno moguće podeliti na samostalne i interaktivne.

Samostalne individualne sportske aktivnosti su one aktivnosti ili sportovi kod kojih se od onoga ko ih upražnjava ne zahteva da imaju bilo kakvu bitnu interakciju sa nekim drugim. Na primer, streljaštvo, bacanje kladiva, trčanje, ili preskakanje prepona, su sve aktivnosti koje onaj koji ih izvodi radi samostalno, bez koordinacije ili interakcije sa drugim osobama (nezavisno da li su članovi istog tima ili ne), izuzev trenera i njemu sličnih osoba.

Interaktivne individualne sportske aktivnosti su one aktivnosti u kojima onaj koji ih upražnjava mora da se koordiniše ili interaguje sa nekom drugom osobom, ali aktivnost ne uključuje koordinisano izvođenje u okviru celog tima kome osoba pripada. Tekvondo, aikido, ples, i tenis, spadaju u ovu vrstu sportskih aktivnosti jer podrazumevaju da osoba koja ih upražnjava mora da reaguje ili koordiniše svoje delanje i izvođenje pokreta sa partnerom ili protivnikom, ali ne i sa timom kojem pripada.

Timske sportske aktivnosti podrazumevaju to da je osoba član tima, i da je neophodno da ona koordiniše svoje aktivnosti i sa ostalim članovima svog tima, i da reaguje i interaguje na aktivnosti protivničkog tima. Primeri ovih aktivnosti su fudbal, košarka, i odbojka.

U narednoj tabeli data je raspodela sportskih aktivnosti kod dece koje se trenutno redovno bave sportom.

Tabela 1 - Raspodela dece po tipu sportskih aktivnosti kojima se bave (Bižić, 2020)

Table 1 - Distribution of children by type of sports activities they engage in (Bižić, 2020)

\begin{tabular}{|l|c|c|c|c|c|}
\hline Tip sportske aktivnosti & Frekvenca & Procenat & $\mathbf{X}^{\mathbf{2}}$ & $\mathbf{d f}$ & $\mathbf{p}$ \\
\hline samostalno individualne & 52 & 78,8 & 61,727 & 2 & $<0,001$ \\
\hline interaktivno individualne & 9 & 13,6 & & & \\
\hline timske & 5 & 7,6 & & & \\
\hline
\end{tabular}

Skoro $80 \%$ dece koja se redovno bave sportom bave se samostalno individualnim sportovima. Zbog malog broja dece koja se trenutno bave sportom, a posebno zbog malog broja dece koja se bave bilo interaktivno individualnim bilo timskim sportskim aktivnostima, nema smisla testirati polne razlike među tipovima sportskih aktivnosti. Ali, nalaz upućuje na to da je druga hipoteza ovog rada takođe potvrđena - preko $90 \%$ dece koja se redovno bave sportskim aktivnostima bave se individualnim, a 
skoro $80 \%$ bavi se specifično samostalno individualnim sportskim aktivnostima.

Daleko je više one dece koja se sportskim aktivnostima bave u okviru kluba ili organizacije - čak $86 \%$ dece. lako je moguće dalje baviti se postojanjem nezadovoljenih potreba za bavljenje sportom kod dece koja se redovno bave sportskim aktivnostima, a koja to ne čine u okviru neke organizacije ili kluba. Kada se radi o razlikama u zadovoljstvu i značaju treniranja kod dece koja se bavi različitim tipovima sportskih aktivnosti, razlika među njima nema. S druge strane, dečaci i njihovi roditelji su nešto manje zadovoljni odnosom trenera prema njima, ali su i kod dečaka i kod devojčica ova zadovoljstva u rangu izuzetno visokog. Mimo ovoga, dečaci i njihovi roditelji su manje zadovoljni i udaljenošću mesta treniranja od mesta stanovanja, pri čemu je njihovo zadovoljstvo na nivou visokog, a zadovoljstvo devojčica i njihovih roditelja na nivou izuzetno visokog. $\mathrm{Na}$ osnovu svih prikazanih analiza može se zaključiti da se redovno bavljenje sportskim aktivnostima vidi kao od velikog značaja kod dece koja se redovno bave sportom u okviru klubova ili organizacija. Ali, stepen zadovoljstva različitim aspektima treniranja je vrlo visok, $i$ to $i$ kod onih koji se bave različitim sportovima, i kod dece različitog pola. Ovo upućuje na zaključak da kod dece koja se već redovno bave sportskim aktivnostima u okviru klubova ili organizacija nema bitno nezadovoljenih želja i potreba, te da ona nisu dobra publika za klubove i organizacije koji bi želeli da privuku decu sa posebnim potrebama.

Postojanje nezadovoljenih želja kod dece koja se ne bave sportskim aktivnostima. Da bi deca koja se ne bave redovno sportskim aktivnostima bilo dobra publika za sportske klubove ili organizacije koje žele da privuku decu sa posebnim potrebama, nije dovoljna činjenica da trenutno ne treniraju nijedan sport. Potrebno je da kod njih postoji jaka nezadovoljena želja za bavljenjem sportskom aktivnošću. U narednoj tabeli data je analiza jačine ove želje kao i značaja koji se pridaje bavljenju sportskim aktivnostima.

Tabela 2 - Želja za redovnim bavljenjem sportskim aktivnostima i njegov opaženi značaj (Bižić, 2020)

Table 2 - Desire to engage in regular sports activities and its perceived importance (Bižić, 2020)

\begin{tabular}{|l|c|c|c|c|c|c|}
\hline Varijabla & $\mathbf{M}$ & $\mathbf{S D}$ & $\mathbf{t}^{1}$ & $\mathbf{d f}$ & $\mathbf{p}$ & Intenzitet \\
\hline $\begin{array}{l}\text { želja roditelja da im se dete } \\
\text { redovno bavi sportom }\end{array}$ & 4,68 & 0,76 & 33,785 & 234 & $<0,001$ & izuzetno jaka \\
\hline $\begin{array}{l}\text { želja deteta da se redovno bavi } \\
\text { sportom }\end{array}$ & 4,31 & 1,09 & 18,290 & 231 & $<0,001$ & jaka \\
\hline značaj treniranja & 4,77 & 0,65 & 42,021 & 234 & $<0,001$ & od izuzetnog značaja \\
\hline
\end{tabular}

${ }^{1}$ test vrednost $=3$

Sada, u savremenim društvima, postoji veliki broj raznovrsnih sportskih udruženja, saveza, instituta, koje se mogu okarakterisati kao sportske organizacije. Naziv koji se najčešće upotrebljava za ovakve institucije je klub, kojim se naglašava da je organizacija centar određenih sportskih zbivanja unutar određene zajednice. Pored roditelja i primarne porodice, koja ima najznačajniju ulogu u razvijanju individualnih sposobnosti i veština kod dece, sportske organizacije značajno doprinose razvijanju socijalizacije, timskog duha, zdravog stila života kod dece. $U$ tom procesu suštinsku ulogu imaju treneri, koji pored sportskog znanja i umeća, moraju posedovati i stručno pedagoško znanje. Treneri koji radi sa decom sa posebnim potrebama treba da priđe svakom detetu ponaosob i podstakne ga na ispoljavanje sopstvene želje i mogućnosti. Podsticanje sportskih potencijala, koje se odvija kroz aktivnosti i programe sportskih organizacija, vrši se individualnim pristupom trenera u saradnji sa roditeljima, kroz iskrenu i direktnu komunikaciju.
Suštinske razlike u komunikaciji sa decom mlađeg i starijeg uzrasta ne postoje. Detetu se prilazi iskreno i direktno bez obzira da li ima tri ili šesnaest godina, sa jedinstvenim ciljem, a to je da se podstakne razvijanje sportskih sposobnosti, koja je od suštinskog značaja za razvoj sveobuhvatnih sposobnosti i inteligencije.

$U$ naučnoj literaturi uglavnom je moguće naći definicije pojma marketinga koje se odnose se na profitni sektor, dok se pojam marketinga u neprofitnoj delatnosti izučavao u mnogo manjem obimu. Međutim, sve više se i u teorijskim istraživanjima i u praksi prihvata činjenica da je marketing potreba koja je neophodna i u sferi sporta. Kada je marketing koncept prihvaćen u privredi i profitnom sektoru i kada je potvrđena njegova ekonomska i društvena efikasnost, počelo se sa razmatranjem u nauci da li je marketing koncepciju moguće primeniti i u vanprivredi - u kulturi, školstvu i zdravstvu. $\mathrm{Na}$ ovo pitanje, 1969. godine, Kotler i Levi su prvi dali definisan pozitivan odgovor, smatrajući da i u vanpriv- 
rednim oblastima egzistira odnos razmene. Takva razmena u vanprivrednoj oblasti, u koju spada sport u svom najširem smislu, odvija se između onih koji kreiraju i pružaju uslugu (sportista, sportskih pedagoga, sportskih radnika) i onih kojima je ta usluga namenjena (publici). Kao predmet razmene, marketing u sportu ima ideju, informaciju i komunikaciju među ljudima, koja ne mora uvek da se odvija direktno na tržištu, već može da se javi i uz veliki broj posrednika.

Specifičnost razvoja marketing komunikacija u sportskim organizacijama neprofitnim organizacijama je ta što pored marketing komunikacija usmerenih ka obezbeđivanju finansijskih izvora od strane države, fondova, donatora i sponzora, treba razviti posebnu marketing strategiju za korisnike, odnosno publiku. Na efikasnost ovakvih institucija najneposredniji uticaj imaju njihovi korisnici, od čijeg načina prihvatanja zavisi pozicioniranje u javnosti. Orijentisanost ka korisniku je posebno važna neprofitnim organizacijama s obzirom da one pružaju različite sportske programe, usluge i ideje i da od vrednosne procene tih programa i usluga od strane korisnika, zavisi opstanak određenog programa.

Osnovna svrha ispitivanja publike šta misle o programima i uslugama određene organizacije jeste da se nauči kako da se komunicira sa njima. Neefikasna komunikacija samo stvara barijeru između organizacije i redovnih ili budućih posetilaca. Prilikom korišćenja koncepcije orijentisane ka korisniku, treba voditi računa o kvalitetu, jedinstvenosti, stručnosti i profesionalnosti. Radi povećanja efektivnosti pružanja usluga korisniku i uzajamno korisne razmene, potrebno je strateški osmisliti kreativnu marketing komunikaciju i adekvatno primeniti marketing program. Za to je potrebno da postoji razvoj operativnog marketing plana, adekvatan izbor ciljnog tržišta, diferenciran pristup potencijalnim korisnicima, administrativna i finansijska podrška marketing aktivnostima, uvođenje interne marketinške poslovne filozofije pre sprovođenja eksternih marketing strategija i iznad svega stručno znanje i iskustvo marketing menadžmenta.

Ciljevi marketinške delatnosti u sportskim organizacijama koja rade sa decom, a posebno sa decom sa posebnim potrebama mogu se definisati i na sledeći način:

- istraživanje tržišta sporta, na osnovu koje se formira poslovna politika, oblikuje identitet sportske organizacije i formira sportski program;

- razvoj broja korisnika-sportista, što podrazumeva zadržavanje starih članova i putem raznovrsnih oblika animacionih programa stvaranje mogućnosti da se potencijalni korisnici-sportisti pretvore u stalne;

- ostvarivanje što većeg samostalnog prihoda, čime bi se sve više smanjivala zavisnost sportske organizacije od finansijera i time bila moguća veća autonomnost u radu i osmišljavanju programa;

- ostvarivanje vidljivosti u javnosti i stvaranje ugleda sportske organizacije.

\section{ZAKLJUČAK / CONCLUSION}

Nadamo se da smo kroz ovaj rad uspeli da pokažemo da čovek i priroda mogu i moraju da idu zajedno. Sport kao velika industrijska grana danas u svetu, svakako može da pomogne u razvoju i podizanju ekološke svesti kod mladih i u Srbiji. Ekologija i sport imaju više toga zajedničkog nego što se na prvu pomisao to čini. Sport bilo kao takmičarski ili u okvirima sportske rekreacije sastavni je deo ekoloških akcija koje obuhvataju problematiku ekologije. Da bi sport mogao dati potrebne i očekivane rezultate, posebno u masovnom sportu, u zajedničkim životom, u sredini zaštićenoj od razhih zagađenja, neophodan je adekvatni odnos celog društva, države i njenih institucija a posebno ljudski faktor prema ekološkoj problematici, jer u zagađenoj, kontaminiranoj okolini sam sport se ne bi mogao dovoljno razvijati. Postoje dve osnovne skupine faktora koji su posebno doprineli pojavi i razvoju ovog novog koncepta u marketinškom komuniciranju. To su tržišni faktori i tehnološki faktori. Značaj fizičke aktivnosti i sporta za decu sa posebnim potrebama je veliki. Savremena defektologija kaže da ne postoji osoba sa posebnim potrebama koja ne može da se uključi u neki vid fizičkog vežbanja i sporta, već samo može postojati samo neodgovarajuća adaptacija kako treninga, i svega ostalog što prati trenažni proces danas. Sport može imati izuzetno pozitivan uticaj na decu naručito za razvoj svesti kod najmlađih o značaju ekologije i zaštite životne sredine u današnjem vremenu i svetu koji nas okružuje.

\section{LITERATURA / REFERENCES}

[1] Bižić, V. (2015). Značaj sporta u školskom uzrastu, sa posebnim osvrtom na značaj borilačkog sporta na primeru kjokušinkai karatea, Međunarodni kongres Ekologija, zdravlje, rad i sport, Banja Luka (pp. 141-158).

[2] Bižić, V. (2020). Značaj različitih marketinških komunikacionih kanala za podsticanje sportskih aktivnosti kod dece sa posebnim potrebama, doktorska disertacija,109, 117. 
[3] Čolin, T. (2005). Obrazovanje netipične dece u tipičnom okruženju: američko iskustvo. Korak ka, bilten za ljude bez predrasuda, 3, Beograd.

[4] Hall, M. (1992). Adventure, Sport and Health Tourism. In: B. Weiler \& M. Hall (Eds.), Special Interest Tourism (pp. 141-158). New York.

[5] Hrnjica, S. (1991). Ometeno dete - uvod u psihologiju ometenih u razvoju. Zavod za udžbenike i nastavna sredstva, Beograd.

[6] Lazor, M., Marković, S., \& Nikolić, S. (2008). Priručnik za rad sa decom sa smetnjama u razvoju. Novosadski humanitarni centar, Novi Sad.

[7] Rajović, V. (2004). Psihosocijalne determinante razvoja i učenja mentalno retardirane dece. Institut za psihologiju, Beograd.
[8] Radoman, V. (2003). Učenici sa razvojnim smetnjama u novoj školi po meri deteta, U: J. Šefer, S. Maksić, S. Joksimović (ur.), Uvažavanje različitosti $i$ obrazovanje (str. 65-70), Institut za pedagoška istraživanja, Beograd.

[9] Šiljak, V., Stefanović, R., Savić, Z., Kocić, J., Toskić, D., Milošević, S. (2019). Uticaj Olimpijskih igara na razvoj Tokia kao „pamentog grada“, Ecologica, 26(94), 271-276.

[10] Štakić, Đ. (2003). Sociologija sporta, Fakultet sporta i fizičkog vaspitanja Univerziteta u Beogradu, Beograd.

[11] Tomić, M. (2003). Marketing u sportu, Astimbo, Beograd. 